\title{
Muscle damage and regeneration: Response to exercise training
}

\author{
Teet Seene ${ }^{*}$, Priit Kaasik \\ Institute of Exercise Biology and Physiotherapy, University of Tartu, Tartu, Estonia; ${ }^{*}$ Corresponding Author: teet.seene@,ut.ee
}

Received 16 April 2013; revised 17 May 2013; accepted 11 June 2013

Copyright (C) 2013 Teet Seene, Priit Kaasik. This is an open access article distributed under the Creative Commons Attribution License, which permits unrestricted use, distribution, and reproduction in any medium, provided the original work is properly cited.

\begin{abstract}
Exercise training influences the function of skeletal muscle, modifying fibre structure, metabolism and promoting the release of growth factors and other signalling molecules. The number of satellite cells under the basal lamina of type I and type IIA muscle fibres increases during endurance training and under the basal lamina of both type II fibres during resistance training. An increase in satellite cells is related to several factors expressing different genes and type II muscle fibre hypertrophy. Insulin-like growth factor-I has a role in the hypertrophy of muscle fibres through the stimulation of the differentiation of satellite cells. The increased mitochondrial biogenesis via adenosine myophosphateactivated protein kinase is accompanied by the suppression of myofibrillar protein synthesis through pathways mediated by mitogen-activated protein kinases and the nuclear factor kappa B. Insulin-like growth factor-I expression is higher in type I fibres. Myostatin, the expression inhibitor of muscle hypertrophy, is higher in type II fibres. The proteasome-, lysosome- and $\mathrm{Ca}^{2+}$-mediated protein degradation is more intensive in fibres with higher oxidative capacity. Both, oxidative capacity and satellite cells number in muscle fibres play important roles in skeletal muscle regeneration. In this review, we explore the regeneration capacity changes in different types of skeletal muscle fibres in response to resistance, endurance and overtraining.
\end{abstract}

Keywords: Skeletal Muscle; Regeneration Capacity; Resistance; Endurance and Overtraining

\section{INTRODUCTION}

The contemporary exercise training process does not simply consist in repetitive exercise but encompasses regular regeneration as an integral part of a successful training program. Systematic recovery periods in the training process are necessary to achieve an augmentation for further performance improvement. Exerciseinduced skeletal muscle damage mainly follows unaccustomed and sustained metabolically demanding training processes [1]. Muscle fibre damage is often caused by excessive strain in contracting fibre, not because of the absolute force developed in the muscle [2]. The anatomic site of myofibrillar injury is the attachment of myofibrils to the extrasarcolemic cytoskeleton [3].

Certain intracellular mechanisms are associated with muscle damage, such as calcium overload, free radical formation and a decrease in energy supply. A fall in cellular adenosine triphosphate (ATP) content is associated with apoptosis and muscle ATP levels can decrease in response to stress [4]. The release of cellular proteins occurs when cellular ATP falls below a critical level, and interference in the energy supply to the muscle membrane is an important factor leading to enzyme efflux [5-7]. The ability to alter mitochondrial content and function is an important adaptive response of the skeletal muscle. It has been shown that skeletal muscle regeneration is accompanied by a marked stimulation of mitochondrial biogenesis concomitant with the onset of muscle fibre differentiation [8].

Muscle fibres regenerate via the activation of quiescent muscle precursor cells (Figure 1) and proceed with the formation of proliferating progenitors that fuse to generate differentiated myofibres [9]. These satellite cells (Sc) activated by muscle injury give rise to intermediate progenitor cells expressing the MyoD and myogenic transcription factor Pax3, which are asymmetrically divided and differentiated into Pax3, Myf-5 and desmin myoblasts [10]. Regeneration in exhausted skeletal muscle, caused by both endurance and strength training, is slow as the lack of insulin-like growth factor-I (IGF-I) 


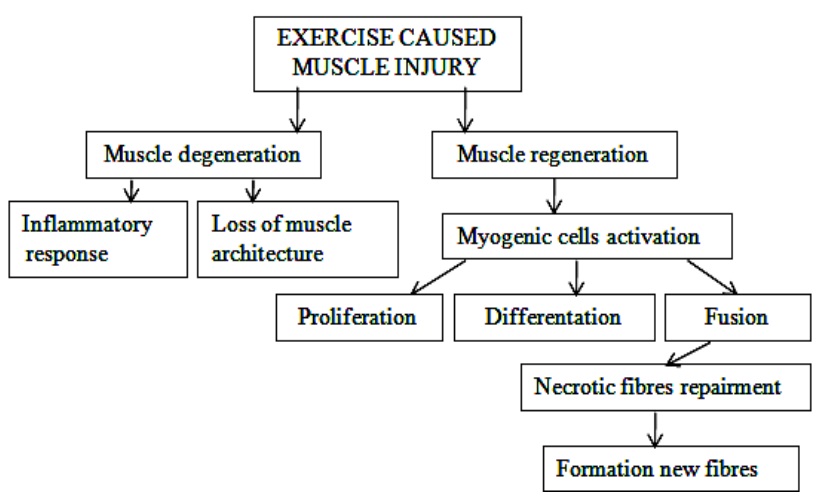

Figure 1. Skeletal muscle repair process after exercise caused muscle damage. Muscle fibres regenerate by activation of satellite cells. Satellite cells activated by muscle injury and express myogenic transcription factors. Regeneration in exercise caused exhausted muscle is slow as lack of several factors prevents the activation of satellite cells under the basal lamina of muscle fibres.

and mechano-growth factor (MGF) prevents the activation of Sc under the basal lamina of muscle fibres.

In this review, the current understandings of the changes in skeletal muscle regeneration capacity in response to resistance, endurance and overtraining and reasons thereof are presented. Morpho-functional characteristics of injured muscle and the role of Sc and different myogenic factors in the repair of myofibres after damage are discussed.

\section{REGENERATION CAPACITY OF SKELETAL MUSCLE FIBRES}

Under the basal lamina, skeletal muscle contains quiescent mononucleated cells characterized by their high level of Pax7 expression- $\mathrm{Sc}$ - which soon after muscle damage activate, divide, proliferate, undergo myogenic differentiation, maturation and form new muscle fibres $[11,12]$. Sc, which develop further into myoblasts, contain a lot of ribosomes, branching granular sarcoplasmic reticulum with widened canals and a well-developed Golgi apparatus [13]. Sometimes Sc also contain centrioles, which confirms that these cells are divided by mitosis. In some of these Sc, sarcoplasm close to the nucleus contains bundles of filaments, which may turn out to be myofilamets [14].

Many growth factors are produced in injured skeletal muscle and influence its regeneration $[11,15]$. Leukaemia inhibitory factor (LIF) stimulates skeletal muscle Sc proliferation and is involved in muscle hypertrophy and regeneration during exercise [16]. Peroxisome proliferator-activated receptor isoform $\delta$ (Ppar $\delta$ ) gene, which regulates skeletal muscle oxidative capacity via Sc proliferation [17] as well as injury induced myokine insulinlike 6 (Ins16) [18] also support muscle regeneration.
Exercise training has the ability to influence the function of muscle fibres modifying their structure and metabolism and promoting the release of growth factors and other signalling molecules, such as nitric oxide, which work through the paracrine system to activate Sc [19]. Oxidative muscle fibres contain a large number of myonuclei and Sc compared with glycolytic fibres [20, 21]. Fast-to-slow fibre transition has been shown to be associated with increases in Sc activation, content and fusion to transforming fibres, especially within the IIB fibres $[22,23]$. The number of Sc in very different stages of development under the basal lamina of type I and type IIA muscle fibres increases during endurance training (ET) $[14,19,24]$. The fact that Sc play a direct role in fast-to-slow fibre transition shows that considerable adaptive capacity resides in myonuclei [25]. The location of $\mathrm{Sc}$ in the postsynaptic region is evidence of the plastic regenerative capacity of this region [13]. If necessary, this kind of cells can join the muscle fibres and increase the area of the synapse and the number of nuclei in the region (Figure 2). Slow-twitch (ST) oxidative muscle fibres contain a large number of Sc in comparison with fast-twitch (FT) glycolytic fibres [20]. In exercising muscle, Sc are able to leave the fibre and form a new population of myogenic cells and are later ready to form new muscle fibres [13]. Regeneration capacity is higher in type I and IIA muscle fibres, where the oxidative capacity and insulin-stimulated glucose uptake is higher in comparison with type IIB/IIX fibres [6,26].

\section{RESPONSE TO RESISTANCE TRAINING}

In resistance training (RT), the repetition regimen plays an important role in the development of muscle fibre hypertrophy as well as regeneration capacity [27, 28]. The increased number of Sc in power lifters shows that Sc make skeletal muscle more responsive to training and regeneration [29]. Sc are provided as additional myonuclei via the proliferation, differentiation and fusion with existing myofibres during muscle hypertrophy [31]. Sc number has shown to increase after RT. The paired box transcription factor Pax 7 plays a critical role in regulating the specification of $\mathrm{Sc}$ and in maintaining the Sc population via self-renewal [31,32]. An increase in $\mathrm{Sc}$ is related to several factors expressing different genes and FT muscle hypertrophy [33,34]. IGF-I is involved in the hypertrophy of muscle fibres via stimulation of the protein synthesis rate. The MGF level increases with the increase in the number of Sc in mature muscle fibres [35].

RT causes muscle hypertrophy in two ways. First, damaged mature fibres regenerate as a result of the fusion with Sc [36]. It is proved by the incorporation of ${ }^{3} \mathrm{H}$ 

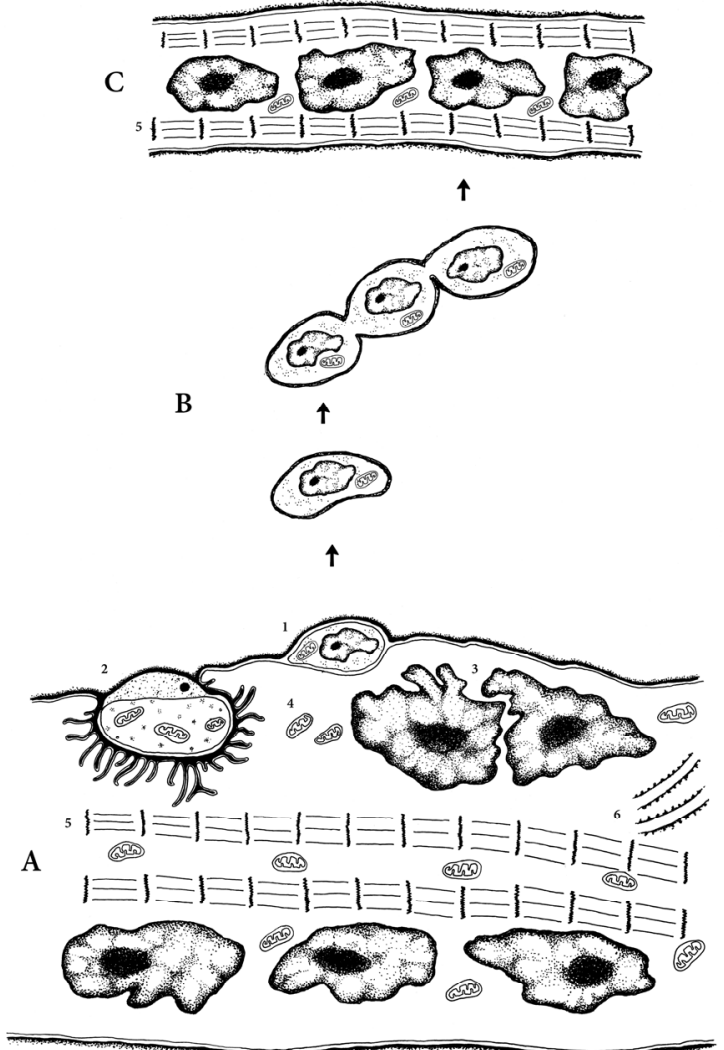

Figure 2. Schematic representation of the skeletal muscle repair process following strenuous exercise: A. Satellite cells $(\mathrm{Sc})$ activation by muscle injury. Sc divide, proliferate, differentiate, mature (B) and form new muscle fibres (C) or fuse with damage mature fibres and gives impulse for regeneration of these fibres. 1 - satellite cell under the based laminea; 2-neuromuscular junction; 3-myonuclei; 4-mitochondria; 5-myofibrils; 6-granular sarcoplasmic reticulum; B. Satellite cells devide, later myosymplasts fuse with each other and form myotubes; C. Myotube.

thymidine into the nucleus of the muscle fibre [37]. As ${ }^{3} \mathrm{H}$ thymidine is not incorporated into the nucleus of a mature muscle fibre, the only option for incorporation is via Sc (Figure 2). The second way is the activation of Sc under the basal lamina of muscle fibres during resistance training (Figure 2). Sc divide and later myosymplasts fuse with each other and form myotubes [36]. As noted, Sc are the source of forming new muscle fibres during RT. Hyperplasia plays a certain role in the process of muscle hypertrophy in RT, even in adults [38].

Skeletal muscle fibres are multinucleated cells, where each myonucleus controls the production of protein synthesis over a finite volume of cytoplasm - the DNA unit or myonuclear domain $[39,40]$. An increase in myonuclei is the source of muscle hypertrophy, but moderate changes in the skeletal muscle size are possible without new myonuclei [41].

\section{RESPONSE TO ENDURANCE TRAINING}

Endurance training (ET) increases the maximum rate of oxygen consumption, influences the enzyme system of the Krebs cycle, electron transport chain, capillary supply, changes in key metabolic enzymes involved in fatty acid activation and does not result in hypertrophy of skeletal muscle fibres [42-44]. Skeletal muscle cross sectional area (CSA) in ET stays on the same level or has a tendency to decrease, particularly in fibres with higher oxidative capacity [13]. This is important from the standpoint of oxygen diffusion distance, the decrease of which supports the increase in oxidative capacity of skeletal muscle during endurance exercise [45]. ET stimulates mitochondrial biogenesis and improves its functional parameters [46]. Increased mitochondrial biogenesis via adenosine monophosphate-activated protein kinase (AMPK) is accompanied by suppression of the myofibrillar protein synthesis through pathways mediated by mitogen-activated protein kinases (MAPK), nuclear factor kappa B (NF-kB) mammalian target of rapamycin (mTOR) and tuberous sklerosis coplex (TSC) [47,48]. Muscle fibres with higher oxidative capacity contain higher quantities of Sc, myonuclei, mitochondria, mRNA, and total ribosomal RNA content. IGF-I expression is also higher in ST fibres $[49,50]$. Myostatin, the expression inhibitor of muscle hypertrophy, is higher in FT fibres $[51,52]$. The proteasome-, lysosome- and $\mathrm{Ca}^{2+}$-mediated protein degradation is more intensive in the fibres, where the oxidative capacity is higher [53]. The components of the degradation system of muscle protein, such as ubiquitin ligases muscle atrophy F-box (MAFbx) and muscle ring finger (MuRF), are about twofold higher in muscle fibres with higher oxidative capacity (ST type I and FT type IIA fibres) [47]. The number of Sc in rat skeletal muscle increased about 3.5 times during ET [54]. Both, oxidative capacity and Sc number in muscle fibres determine muscle regenerative capacity. In ET, muscle protein synthesis and degradation are balanced so that ST type I and FT type IIA fibre size does not increase. This process is supported by the turnover rate of muscle protein [45].

ET programs in a variety of forms improve the energetic potential of skeletal muscle and support the effective functioning of the myofibrillar apparatus [55,56]. Activation of AMPK in response to ET includes the induction of glucose transport, glycogen metabolism, fatty acid oxidation and transcriptional regulation of structural genes [57] and $\alpha 1$ isoform of AMPK, which regulates skeletal muscle growth [58].

Exercise training supports muscle regeneration capacity (Figure 2 and 3). It is important from the standpoint of top level endurance athletes and also recreational athletes who exercise regularly as regular exercise training 
is the way for the relatively fast regeneration of muscle fibres.

\section{REGENERATION OF MUSCLE CONTRACTILE APPARATUS IN RESISTANCE AND ENDURANCE TRAINING}

\subsection{Regeneration Capacity Changes in Response to Resistance Training}

RT increases the CSA of the whole muscle and individual muscle fibres, and increases myofibrillar size and number [27]. The hypertrophy response to RT is related to the activation of Sc in the early stage of training [27]. RT also causes other morphological adaptations, such as hyperplasia, changes in muscle fine architecture, in myofilament density and in the structures of connective tissue [27]. RT mainly causes an increase in the CSA of IIX/IIB and IIA fibres. Structural changes in skeletal muscle during RT are fibre specific. FT fibres are more vulnerable to damage than ST [59]. In resistance training, type IIX/IIB fibres have twisted myofibrils in a relatively small area and they have lost connection with the neighbouring structures [13]. Damage caused by RT in skeletal muscle is also stimulus for regeneration due to muscle growth and promoting signalling events arising from the mechanical deformation of fibres, hormones and immune/inflammatory responses [60]. RT enhances the synthesis rate of myofibrillar proteins, not of sarcoplasmic proteins, and this is related to the mammalian target of rapamycin complex by activating proteins with mitogen activated protein kinase signalling [48]. Structural changes with exercise-induced muscle damage are associated with the influence of gene expression strengthening the muscle, protecting the tissue against further injury [61], and an increased protein turnover rate [13]. Recovery from damaging RT is slower as a result of age, whereas there are no age-related differences in recovery from less damaging metabolic fatigue [62]. Recovery from RT, during which the power of exercise increases less than 5\% per session, causes hypertrophy of both FT and ST muscle fibres and an increase in the myonuclear number. This is achieved via Sc fusion (Figure 2) with damaged fibres or the formation of new muscle fibres as a result of myoblasts' fusion in order to maintain myonuclear domain size [37]. RT increases the level of IGF-I and MGF in skeletal muscle and these factors support faster recovery of muscle tissue [6].

\subsection{Regeneration Capacity Changes in Response to Endurance Training}

ET causes most changes in type I and IIA muscle fibres. The day following ET, significant destructive changes are visible in the myofibrils of these fibres. This

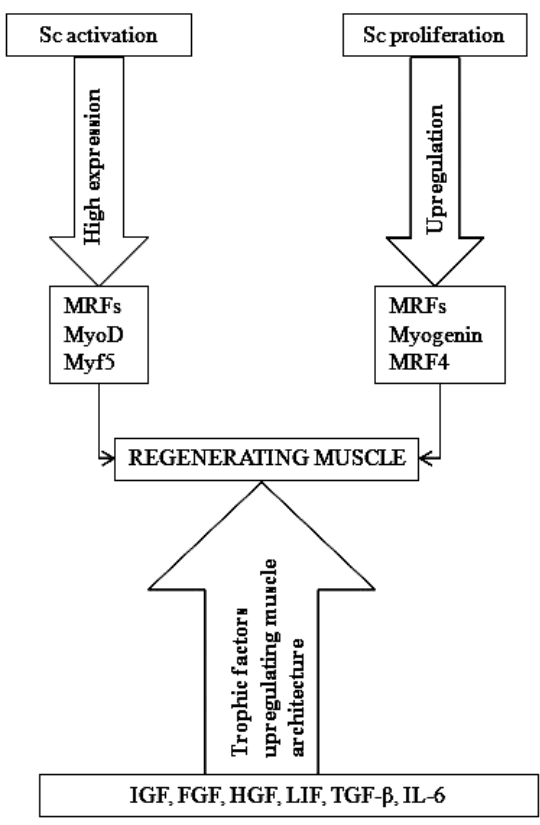

Figure 3. Molecular events regulating satellite cell activation in exercise damaged skeletal muscle regeneration process. Both resistance and endurance exercise stimulate muscle regeneration. Resistance exercise increase the level of insulin-like growth factor 1 and mechano-growth factor in skeletal muscle and these factors support faster recovery of muscle tissue. Endurance exercise increase the number of satellite cells under the basal lamina of type I and IIA fibres and increase the regeneration capacity, particularly metabolic adaptaion of muscle. MRFs - muscle regulatory factors; MyoD - myoblast determination protein; Myf5-myogenic factor 5; MRF4muscle regulatory factor 4; IGF-insulinlike growth factor; FGF - fibroblasts growth factor; MGF-mechano-growth factor; HGF-hepatocyte growth factor; LIFleukemia inhibitory factor; TGF- $\beta$-transforming growth factor- $\beta$ family; IL-6interleukin-6; Sc — satellite cell.

damage includes the destruction of myosin and actin filaments and the disturbance of the regularity of Z-line in some sarcomeres [19]. In some A-discs, myosin filaments are absent and the destruction may cover the whole sarcomere. These structural changes are in accordance with biochemical ones [19,45]. Small structural rearrangements take place in type IIB fibres during ET as these fibres are less recruited. The number of mitochondria in type IIB fibres during ET does not increase significantly; they are located in small groups near nuclei and between myofibrils on the level of Z-line, but not in each sarcomere [13].

AMPK is activated in response to ET [63] and related 
to the metabolic adaptation of skeletal muscle. AMPK function includes glucose transport, glycogen metabolism, fatty acid oxidation and transcriptional regulation of structural muscle genes [57]. $\alpha 1$ isoform of AMPK is the regulator of skeletal muscle growth and $\alpha 2$ isoform regulates metabolic adaptation [58]. Protein turnover in skeletal muscle is relatively slow, particularly contractile proteins and aerobic endurance exercise training stimulates protein turnover [45]. The turnover rate of myosin heavy chain (MyHC) and myosin light chain (MyLC) isoforms provides a mechanism by which the type and amount of protein changes in accordance with the needs of the contractile machinery during adaptation to ET [64]. ET mainly increases the number of Sc under the basal lamina of type I and IIA fibres and increases the regeneration capacity (Figures $\mathbf{2}$ and $\mathbf{3}$ ) of these fibres [13].

It is well known that different modes of mechanical activity result in the selective up- and down-regulation of myosin MyHC isoforms in FT skeletal muscle in humans and animals. Most studies have shown that the relative content of MyHC IIx and IIb isoforms decreases during RT. A low number of repetitions during the training session and a low volume of RT cause relatively small hypertrophy of muscle. However, the highest increase in muscle strength and a small increase in the relative content of MyHC IIb isoform were simultaneously registered in FT muscles [65]. It seems that both in case of RT and ET, an increase in the training volume decreases the relative content of MyHC IIb isoform in FT skeletal muscles.

The mechanism associated with activity-induced shifts in myosin expression is the key to understanding the plasticity of skeletal muscle as the hypertrophied muscle fibre has adapted to a chronic overload via an alteration in its phenotype [66]. The mechanisms involved in regulating changes in the myosin expression and in the muscle mass may have different sensitivities to mechanical load [67].

\section{RESPONSE TO OVERTRAINING}

An excessive volume of ET leads to exercise intolerance. Problems with recovery have been shown to occur in animal experiments when exercise training time reaches $10 \%$ within a $24 \mathrm{~h}$ period $[6,68]$. A significant decrease in physical work capacity during exhaustive exercise as compared to the recommended training protocol suggests that lack of recovery in the training protocol leads to overtraining syndrome. If the exercise session lasts too long and training sessions are so frequent that they interrupt the recovery phase, the necessary adaptation does not occur $[69,70]$. The importance of recovery is evident from the fact that a much longer recovery time is needed after symptoms of overtraining appear [68]. Deterioration of the capillary network decreases the exchange of oxygen between capillaries and muscle fibres. As a result, muscle oxidative and regeneration capacity decreases as well as the Sc number under the basal lamina of muscle fibres [71,72]. A decrease in the number of Sc means that new muscle fibres do not form as quickly as in intact muscle and damaged fibres do not regenerate appropriately since Sc do not fuse with damaged fibres [6].

Lack of Sc, a decreased differentiation of myosymplasts and level of transcription factors (MyD family), except for myostatin, decrease muscle regeneration capacity (Figure 3). Lack of MGF leads to apoptosis. If muscle fibres do not regenerate, muscle atrophy develops [6]. Only myostatin and heat shock protein (HSP-70) synthesis increases in atrophied muscle. A decrease in the synthesis rates of muscle proteins, particularly myofibrillar proteins, and increased protein degradation lead to the "wastage" of muscle. A decrease in myonuclei number and DNA damage lead to a decrease in DNA units in overtrained skeletal muscle [68]. Lack of myonuclei accompanied by decreased synthesis and an increased degradation rate of muscle proteins, particularly myofibrillar proteins [68], lead to a decrease in the muscle growth and regenerative capacity in overtraining caused myopathic skeletal muscle [6,71]. It has been shown that the inflammatory cytokines cycloo xy genase-2 (COX-2) and phosphatidic acid (PA) may play role in the inhibition of skeletal muscle growth induced by overtraining [73].

\section{REGENERATION CAPACITY IN OVERTRAINING CAUSED MYOPATHIC MUSCLE}

The DNA content in muscle, and the protein and DNA ratio in FT muscles decreases during exhaustion showing signs of myopathy as a result of muscular overload [68]. As far as is presently known, overtraining caused myopathy is characterized by slow turnover of $\mathrm{MyHC}$ in FT muscle fibres, depressed neuromuscular and depressed $\alpha$-motoneuron excitability [6]. Pro-inflammatory cytokine profile changes also constitute a risk for overtraining syndrome [74,75]. Vitamin D insufficiency is the reason for the increased concentration of the inflammatory cytokine TNF- $\alpha$ [76].

The decreased synthesis and increased degradation rate of contractile proteins, which was observed in overtraining caused myopathic muscle, is in good agreement with the increased occurrence of destructive processes in FT fibres $[6,68]$. Contrary to the decreased turnover rate of contractile proteins, overtrained athletes show a persistent high synthesis rate and concentration of HSP, which might show an increased stress tolerance of affected cells and mediate the cellular repair process [77]. During migratory flight, which can last 50 - 100 h, mus- 
cle damage occurs mainly in young, relatively unadapted (untrained) birds. Experienced migrants may avoid damage behaviourally, or have efficient biochemical and physiological defence systems against muscle injury [78]. Damaged muscle tissue releases cytokines (Figure 3), which act in the hypothalamus to re-set the regulatory mechanisms which, among other things, shut down functions that might promote further damage.

\section{ROLE OF CYTOKINES IN REGENERATING SKELETAL MUSCLE}

Cytokines play an important role in the exercise-induced immune reaction and exercise-related metabolic and cellular signal transduction, and they are also capable of increasing HSP synthesis [79]. It is possible that HSP may act as a cytokine in reaction to exhaustive exercise, stimulate tumour necrosis factor-alpha (TNF- $\alpha$ ), interleukin (IL)- $\beta$, and IL- 8 in monocytes, and activate CD 14-dependent and $\mathrm{Ca}^{2+}$-dependent pathways [80]. LIF has been shown as a trauma factor for injured skeletal muscle due to its myotrophic action and in response to muscle injury together with IL-6 they are upregulated in injured muscle fibres and mononuclear cells at the site of the muscle injury [81]. High concentration of proinflammatory cytokine TNF- $\alpha$ promotes damage and impairs skeletal muscle [82] and vitamin D supplementation improves the cytokine profile in patients with chronic diseases [84] but not in healthy individuals $[85,86]$.

Muscle damage during exhaustive exercise increases athletes' energy and protein needs [87]. It has been shown that basal metabolic rate increases by $32 \%$ after skeletal muscle trauma [88] as the acquisition of new muscle mass is an energy-costly process in athletes and a $2300-3500 \mathrm{kcal}$ surplus is required to build each pound of new muscle tissue [89].

Contracting muscle fibres release cytokines, which in turn create many effects in other organs, including the brain. Sooner or later, all these different mechanisms create sensations of fatigue and exhaustion in the mind of the exercising subject [90]. Exhaustive exercise induces an anti-inflammatory effect in skeletal muscle, especially in FT muscle fibres and a pro-inflammatory effect in adipose tissue [91]. This effect contributes to increased lipolysis to provide energy for the exercising muscle.

Muscle fibre phenotype maintenance and transition depends on motoneuron-specific impulse patterns, neuromuscular activity and mechanical load. Depending on the type, intensity and duration of changes in any of these factors, muscle fibres adjust their phenotype to meet the altered functional demands [66].

\section{CONCLUSION}

Exercise-induced skeletal muscle damage follows un- accustomed training processes. Muscle damage is caused by excessive strain in contracting fibre. Systematic recovery periods in the training process are necessary for performance improvement. Growth factors play a certain role in injured skeletal muscle and influence its regeneration. LIF stimulates skeletal muscle Sc proliferation and is involved in muscle hypertrophy and regeneration during exercise (Figure 1). Ppar $\delta$ gene, which regulates skeletal muscle oxidative capacity via Sc proliferation, and injury-induced myokine Insl6 also support muscle regeneration. Oxidative muscle fibres contain a large number of myonuclei and Sc compared with glycolytic fibres. The number of Sc under the basal lamina of type I and type IIA muscle fibres increases during ET and these cells are in very different stages of development. Sc number increases during chronic RT. The paired box transcription factor Pax 7 plays a critical role in regulating the specification of Sc and in maintaining the Sc population via self-renewal. An increase in Sc is related to several factors expressing different genes and FT muscle hypertrophy. IGF-I have a role in the hypertrophy of muscle fibres through the stimulation of the differentiation of Sc. The MGF level increases with the increase in the number of Sc in muscle fibres. Increased mitochondrial biogenesis via AMP-activated AMPK is accompanied by suppression of the myofibrillar protein synthesis through pathways mediated by MAPK and NF-kB. Muscle fibres with higher oxidative capacity contain more Sc, myonuclei, mitochondria, mRNA, and have higher total ribosomal RNA content. IGF-I expression is also higher in ST fibres. Myostatin, the expression inhibitor of muscle hypertrophy, is higher in FT fibres. The proteasome-, lysosome- and $\mathrm{Ca}^{2+}$-mediated protein degradation is more intensive in fibres with higher oxidative capacity. The components of the degradation system of muscle proteins, such as ubiquitin ligases MAFbx and MuRF, are higher in muscle fibres with higher oxidative capacity. Both, oxidative capacity and Sc number in muscle fibres play an important role in skeletal muscle regeneration (Figure 2). Muscle protein synthesis and degradation are balanced in ET so that fibre size does not increase. This process is supported by the turnover rate of muscle protein. ET improves the energetic potential of skeletal muscle and supports the effective functioning of the myofibrillar apparatus. Activation of AMPK in response to ET includes an induction of glucose transport, glycogen metabolism, fatty acid oxidation and transcriptional regulation of structural genes and $\alpha 1$ isoform of AMPK, which regulates skeletal muscle growth. If the exercise session lasts too long, the training sessions are too frequent and interrupt the recovery phase, adaptation does not occur and overtraining syndrome develops. The decreased synthesis and increased degradation rate of contractile proteins are in accordance with the increase in destructive processes in muscle and lead to the decrease 
in the regeneration capacity in overtrained skeletal muscle. Cytokines play an important role in the exerciseinduced immune reaction, exercise-related metabolic and cellular signal transduction and the increase in HSP synthesis. HSP may act as a cytokine during exhaustive exercise, stimulate TNF- $\alpha$, IL- $\beta$, and IL- 8 in monocytes, and activate $\mathrm{CD}$ 14-dependent and $\mathrm{Ca}^{2+}$-dependent pathways. LIF, the trauma factor for injured skeletal muscle due to its myotrophic action and in response to muscle injury together with IL-6 are upregulated in injured muscle fibres and mononuclear cells in case of muscle injury (Figure 3). High concentration of pro-inflammatory cytokine TNF- $\alpha$ promotes damage and impair of skeletal muscle and vitamin $\mathrm{D}$ supplementation improves the cytokine profile in patients with chronic diseases.

\section{ACKNOWLEDGEMENTS}

This study was supported by the funds of the Ministry of Education and Research of the Republic of Estonia, research project number TKKSB 1787.

We would like to thank Helen Kaptein for English language editing and Piret Pärsim for technical expertise.

\section{REFERENCES}

[1] Kendall, B. and Eston, R. (2002) Exercise-induced muscle damage and the potential protective role of estrogen. Sports Medicine, 32, 103-123.

[2] Kibler, W.B. and Chandler, T.J. (1998) Musculoskeletal and orthopedic considerations. In: Kreider, R.B., Fry, A.C. and O'Toole, M.L., Eds., Overtraining in Sport, Human Kinetics, Champaign, 169-190.

[3] Fridén, J., Leiber, R.L. and Thornell, L.E. (1991) Subtle indications of muscle damage following eccentric contractions. Acta Physiologica Scandinavica, 142, 523-524.

[4] Perrey, S. and Rupp, T. (2009) Altitude-induced changes in muscle contractile properies. High Altitude Medicine \& Biology, 10, 175-182. doi:10.1089/ham.2008.1093

[5] Gibala, M. (2009) Molecular responses to high-intensity interval exercise. Applied Physiology, Nutrition, and Metabolism, 34, 428-432. doi:10.1139/H09-046

[6] Seene, T., Umnova, M., Kaasik, P., Alev, K. and Pehme, A. (2008) Overtraining injuries in athletic population. In: Tiidus, P.M. Ed., Skeletal Muscle Damage and Repair, Human Kinetics, Champaign, 305-307.

[7] Wijnberg, I.D., van Dam, K.G., Graaf-Roelfsema, E., Keizer, H.A., van Ginneken, M.M., Barneveld, A., Breda, E. and van der Kolk, J.H. (2008) (Over)training effects on quantitative electromyography and muscle enzyme activities in standardbred horses. Journal of Applied Physiology, 105, 1746-1753.

doi:10.1152/japplphysiol.01272.2007

[8] Duguez, S., Féasson, L., Denis, C. and Freyssenet, D. (2002) Mitochondrial biogenesis during skeletal muscle regeneration. American Journal of Physiology. Endocrinology and Metabolism, 282, E802-E809.
[9] Wagers, A.J. and Conboy, I.M. (2005) Cellular and molecular signatures of muscle regeneration: Current concepts and controversies in adult myogenesis. Cell, 122, 659-667. doi:10.1016/j.cell.2005.08.021

[10] Conboy, I.M. and Rando, T.A. (2002) The regulation of Notch signaling controls satellite cell activation and cell fate determination in postnatal myogenesis. Developmental Cell, 3, 397-409. doi:10.1016/S1534-5807(02)00254-X

[11] Charge, S.B. and Rudnicki, M. A. (2004) Cellular and molecular regulation of muscle regeneration. Physiological Reviews, 84, 209-238.

[12] Mauro, A. (1961) Satellite cell of skeletal muscle fibres. The Journal of Biophysical and Biochemical Cytology, 9, 493-495.

[13] Seene, T., Kaasik, P. and Umnova, M. (2009) Structural rearrangements in contractile apparatus and resulting skeletal muscle remodelling: Effect of exercise training. Journal of Sports Medicine and Physical Fitness, 49, 410-423.

[14] Umnova, M. and Seene, T. (1991) The effect of increased functional load on the activation of satellite cells in the skeletal muscle of adult rats. The International Journal of Sports Medicine, 12, 501-504.

[15] Grounds, M.D. (1999) Muscle regeneration: Molecular aspects and therapeutic implications. Current Opinion in Neurology, 12, 535-543.

[16] Broholm, C. and Pedersen, B.K. (2010) Leukaemia inhibitory factor-An exercise induced myokine. Exercise Immunology Review, 16, 77-85.

[17] Angione, A.R., Jiang, C., Pan, D., Wang, Y.-X. and Kuang, S. (2011) PPAR $\delta$ regulates satellite cell proliferation and skeletal muscle regeneration. Skeletal Muscle, 1, 1-16.

[18] Zeng, L., Akasaki, Y., Sato, K., Ouchi, N., Izumiya, Y. and Walsh, K. (2010) Insulin-like 6 is induced by muscle injury and functions as a regenerative factor. The Journal of Biological Chemistry, 285, 36060-36069.

[19] Magaudda, L., Di Mauro, D., Trimarchi, F. and Anastasi, G. (2004) Effects of physical exercise on skeletal muscle fiber: ultrastructural and molecular aspects. Basic Applied Myology, 14, 17-21.

[20] Gibson, M.C. and Schultz, E. (1982) The distribution of satellite cells and their relationship to specific fiber types in soleus and extensor digitorum longus muscles. The Anatomical Record, 202, 329-337. doi:10.1002/ar.1092020305

[21] Gibson, M.C. and Schultz, E. (1983) Age-related differrences in absolute numbers of skeletal muscle satellite cells. Muscle \& Nerve, 6, 574-580. doi:10.1002/mus.880060807

[22] Putman, C.T., Düsterhöft, S. and Pette, D. (2000) Satellite cell proliferation in low frequency-stimulated fast muscle of hypothyroid rat. American Journal of Physiology. Cell Physiology, 279, C682-C690.

[23] Putman, C.T., Sultan, K.R., Wassmer, T., Bamford, J.A., Skorjanc, D. and Pette, D. (2001) Fiber-type transitions and satellite cell activation in low-frequency-stimulated muscles of young and aging rats. The Journal of Geron- 
tology, Series A, Biological Sciences and Medical Sciences, 56, B510-B519. doi:10.1093/gerona/56.12.B510

[24] Apell, H.J., Forsberg, S. and Hollmann, W. (1988) Satellite cell activation in human skeletal muscle after training: Evidence for muscle fiber neoformation. The International Journal of Sports Medicine, 9, 297-299.

[25] Martins, K.J., Gordon, T., Pette, D., Dixon, W.T., Foxcroft, G.R., McLean, I.M. and Putman, C.T. (2006) Effect of satellite cell ablation on low-frequency-stimulated fastto-slow fibre-type transitions in rat skeletal muscle. Journal of Physiology, 572, 281-294.

[26] Mackrell, J.G. and Cartee, G.D. (2012) A novel method to measure glucose uptake and myosin heavy chain isoform expression of single fibers from rat skeletal muscle. Diabetes, 61, 995-1003.

[27] Folland, J.P. and Williams, A.G. (2007) The adaptations to strength training: morphological and neurological contributions to increased strength. Sports Medicine, 37, 145168.

[28] Fry, A.C. (2004) The role of resistance exercise intensity on muscle fibre adaptations. Sports Medicine, 34, 663679.

[29] Thornell, L.E., Lindström, M., Renault, V., Mouly, V. and Butler-Browne, G.S. (2003) Satellite cells and training in the elderly. Scandinavian Journal of Medicine and Science in Sports, 13, 48-55.

[30] Hawke, T.J. and Garry, D.J. (2001) Myogenic satellite cells: Physiology to molecular biology. Journal of Applied Physiology, 91, 534-551.

[31] Ishido, M., Uda, M., Kasuga, N. and Masuhara, M. (2009) The expression patterns of Pax7 in satellite cells during overload-induced rat adult skeletal muscle hypertrophy. Acta Physiologica, 195, 459-469. doi:10.1111/j.1748-1716.2008.01905.x

[32] Zammit, P.S., Golding, J.P., Nagata, Y., Hudon, V., Partridge, T.A. and Beauchamp, J.R. (2004) Muscle satellite cells adopt divergent fates a mechanism for self-renewal? The Journal of Cell Biology, 166, 347-357.

[33] Carson, J.A., Nettleton, D. and Reecy, J.M. (2002) Differential gene expression in the rat soleus muscle during early work overload-induced hypertrophy. Official Publication of the Federation of American Societies for Experimental Biology/FASEB Journal, 16, 207-209.

[34] Hespel, P., Op’t Eijnde, B., van Leemputte, M., Ursø, B., Greenhaff, P.L., Labarque, V., Dymarkowski, S., van Hecke, P. and Richter, EA. (2001) Oral creatine supplementation facilitates the rehabilitation of disuse atrophy and alters the expression of muscle myogenic factors in humans. Journal of Physiology, 536, 625-633. doi:10.1111/j.1469-7793.2001.0625c.xd

[35] Philippou, A., Papageorgiou, E., Bogdanis, G., Halapas, A., Souria, A., Maridaki, M., Pissimissis, N. and Koutsilieris, M. (2009) Expression of IGF-1 isoforms after exercise-induced muscle damage in humans: Characterization of the MGF E peptide action in vitro. In Vivo, 23, 567-575.

[36] Allen, D.L., Roy, R.R. and Edgerton, V.R. (1999) Myonuclear domains in muscle adaptation and disease. Mus- cle \& Nerve, 22, 1350-1360.

[37] Seene, T., Pehme, A., Alev, K., Kaasik, P., Umnova, M. and Aru, M. (2010) Effects of resistance training on fastand slow-twitch muscles in rats. Biology of Sport, 27, 221-229.

[38] Hunter, G.R., McCarthy, J.P. and Bamman, M.M. (2004) Effects of resistance training on older adults. Sports Medicine, 34, 329-348. doi:10.2165/00007256-200434050-00005

[39] Cheek, D.B. (1985) The control of cell mass and replication. The DNA unit-A personal 20-year study. Early Human Development, 12, 211-239.

[40] Hall, Z.W. and Ralston, E. (1989) Nuclear domains in muscle cells. Cell, 59, 771-772. doi:10.1016/0092-8674(89)90597-7

[41] Kadi, F., Schjerling, P., Andersen, L.L., Charifi, N., Madsen, J.L.,Christensen, L.R. and Andersen, J.L. (2004) The effects of heavy resistance training and detraining on satellite cells in human skeletal muscles. Journal of Physiology, 558, 1005-1012.

[42] Baldwin, K.M. and Haddad, F. (2002) Skeletal muscle plasticity: Cellular and molecular responses to altered physical activity paradigms. American Journal of Physical Medicine and Rehabilitation, 81, S40-S51.

[43] Holloszy, J.O. and Booth, F.W. (1976) Biochemical adaptations to endurance exercise in muscle. Annual Review of Physiology, 38, 273-291.

[44] Hood, D.A. (2001) Invited review: Contractile activityinduced mitochondrial biogenesis in skeletal muscle. Journal of Applied Physiology, 90, 1137-1157.

[45] Seene, T., Kaasik, P. and Alev, K. (2011) Muscle protein turnover in endurance training: A review. The International Journal of Sports Medicine, 32, 905-911.

[46] Hood, D.A. (2009) Mechanisms of exercise-induced mitochondrial biogenesis in skeletal muscle. Applied Physiology, Nutrition, and Metabolism, 34, 465-472.

[47] Van Wessel, T., de Haan, A., van der Laarse, W.J., Jaspers, R.T. (2010) The muscle fiber type-fiber size paradox: Hypertrophy or oxidative metabolism? European Journal of Applied Physiology, 110, 665-694.

[48] Moore, D.R., Atherton, P.J., Rennie, M.J., Tarnopolsky, M.A. and Phillips, S.M. (2011) Resistance exercise enhances mTOR and MAPK signalling in human muscle over that seen at rest after bolus protein ingestion. Acta Physiologica, 201, 365-372.

[49] Bodine, S.C., Stitt, T.N., Gonzalez, M., Kline, W.O., Stover, G.L., Bauerlein, R., Zlotchenko, E., Scrimgeour, A., Lawrence, J.C., Glass, D.J. and Yancopoulos, G.D. (2001) Akt/mTOR pathway is a crucial regulator of skeletal muscle hypertrophy and can prevent muscle atrophy in vivo. Nature Cell Biology, 3, 1014-1019.

[50] Stitt, T.N., Drujan, D., Clarke, B.A., Panaro, F., Timofeyva, Y., Kline, W.O., Gonzalez, M., Yancopoulos, G.D. and Glass, D.J. (2004) The IGF-1/PI3K/Akt pathway prevents expression of muscle atrophy-induced ubiquitin ligases by inhibiting FOXO transcription factors. Molecular Cell, 14, 395-403.

[51] Lee, S.J. and McPherron, A.C. (2001) Regulation of 
myostatin activity and muscle growth. Proceedings of the National Academy of Sciences of the United States of America, 98, 9306-9311.

[52] Zimmers, T.A., Davies, M.V., Koniaris, L.G., Haynes, P., Esquela, A.F., Tomkinson, K.N., McPherron, A.C., Wolfman, N.M. and Lee. S.-J. (2002) Induction of cachexia in mice by systemically administered myostatin. Science, 296, 1486-1488.

[53] Van der Vusse, G.J., Glatz, J.F., Stam, H.C. and Reneman, R.S. (1992) Fatty acid homeostasis in the normoxic and ischemic heart. Physiological Reviews, 72, 881-940.

[54] Seene, T. and Umnova, M. (1992) Relations between the changes in the turnover rate of contractile proteins, activation of satellite cells and ultra-structural response of neuromuscular junctions in the fast-oxidative-glucolytic muscle fibres in endurance trained rats. BAM, 2, 39-46.

[55] Harris, B.A. (2005) The influence of endurance and resistance exercise on muscle capillarization in the elderly: A review. Acta Physiologica Scandinavica, 185, 89-97.

[56] Yeo,W.K., Paton, C.D., Garnham, A.P., Burke, L.M., Carey, A.L. and Hawley, J.A. (2008) Skeletal muscle adaptation and performance responses to once a day versus twice every second day endurance training regimens. Journal of Applied Physiology, 105, 1462-1470.

[57] Hardie, D.G. and Sakamoto, K. (2006) AMPK: A key sensor of fuel and energy status in skeletal muscle. Physiology, 21, 48-60.

[58] McGee, S.L., Kristy, J., Mustard, D., Hardie, D.G. and Baar, K. (2008) Normal hypertrophy accompanied by phosphoryation and activation of AMP-activated protein kinase $\alpha 1$ following overload in LKB1 knockout mice. The Journal of Physiology, 586, 1731-1741.

[59] Sjöström, M., Johansson, C. and Lorentzon, R. (1988) Muscle pathomorphology in $\mathrm{m}$. quadericeps of marathon runners. Early signs of strain disease or functional adaptation? Acta Physiolpgica Scandinavica, 132, 537-541.

[60] Spiering, B.A., Kraemer, W.J., Anderson, J.M., Armstrong, L.E., Nidl, B.C., Volek, J.S. and Maresh, C.M. (2008) Resistance exercise biology: Manipulation of resistance exercise programme variables determines the responses of cellular and molecular signalling pathways. Sports Medicine, 38, 527-540.

[61] Schoenfeld, B.J. (2012) Does exercise-induced muscle damage play a role in skeletal muscle hypertrophy? Journal of Strength and Conditioning Research, 26, 14411453.

[62] Fell, J.W. and Williams, A.D. (2008) The effect of aging on skeletal-muscle recovery from exercise: Possible implications for the aging athlete. Journal of Aging and Physical Activity, 16, 97-115.

[63] Winder, W.W. and Hardie, D.G. (1996) Inactivation of acetyl-CoA carboxylase and activation of AMP-activated protein kinase in muscle during exercise. The American Journal of Physiology, 270, E299-E304.

[64] Alev, K., Kaasik, P., Pehme, A., Aru, M., Parring. A.-M., Elart, A. and Seene, T. (2009) Physiological role of myosin light and heavy chain isoforms in fast- and slowtwitch muscles: Effect of exercise. Biology of Sport, 26,
215-234.

[65] Pehme, A., Alev, K., Kaasik, P., Julkunen, A. and Seene, T. (2004) The effect of mechanical loading on the MyHC synthesis rate and composition in rat plantaris muscle. The International Journal of Sports Medicine, 25, 332338.

[66] Pette D. (2001) Historical perspectives: Plasticity of mammalian skeletal muscle. Journal of Applied Physiology, 90, 1119-1124.

[67] Hernandez, J.M., Fedele, M.J. and Farrell, P.A. (2000) Time course evaluation of protein synthesis and glucose uptake after acute resistance exercise in rats. Journal of Applied Physiology, 88, 1142-1149.

[68] Seene, T., Kaasik, P., Alev, K., Pehme, A. and Riso, E.M. (2004) Composition and turnover of contractile proteins in volume-overtrained skeletal muscle. The International Journal of Sports Medicine, 25, 438-445.

[69] Foster, C., Synder, A. and Welsh, R. (1999) Monitoring of training, warm up, and performance in athletes. In: Lehmann, M., Foster, C., Gastmann, U., Keizer, H. and Steinacker, J.M., Eds., Overload, Performance Incompetence, and Regeneration in Sport, Kluwer-Academic/ Plenum Press, New York, 43-51. doi:10.1007/978-0-585-34048-7 4

[70] Lehmann, M., Gastmann, U., Baur, S., Liu, Y., Lormes, W., Opitz-Gress, A., Reisnecker, S., Simsch, C. and Steinacker, J.M. (1999) Selected parameters and mechanisms of peripheral and central fatigue and regeneration in overtrained athletes. In: Lehmann, M., Foster, C., Gastmann, U., Keizer, H. and Steinacker, J.M., Eds., Overload, Performance Incompetence, and Regeneration in Sport, Kluwer-Academic/Plenum Press, New York, 7-25. doi:10.1007/978-0-585-34048-7 2

[71] Kaasik, P. and Seene, T. (2010) The overtraining syndrome: Reflexion in skeletal muscle. Gazzetta Medica Italiana Archivio per le Scienze Mediche, 169, 311-319.

[72] Seene, T., Umnova, M. and Kaasik, P. (1999) The exercise myopathy. In: Lehmann, M., Foster, C., Gastmann, U., Keizer, H. and Steinacker, J.M., Eds., Overload, Performance Incompetence, and Regeneration in Sport, Kluwer Academic Plenum Publishers, New York, 119-130. doi:10.1007/978-0-585-34048-7_9

[73] Xiao, W. and Dong, C.J. (2012) Effect of overtraining on skeletal muscle growth and gene expression. The International Journal of Sports Medicine, 33, 846-853.

[74] Moldoveanu, A.I., Shephard, R.J. and Shek, P.N. (2001) The cytokine response to physical activity and training. Sports Medicine, 31, 115-144.

[75] Smith, L.L. (2000) Cytokine hypothesis of overtraining: A physiological adaptation to excessive stress? Medicine and Science Sports and Exercise, 32, 317-331.

[76] Wills, K.S., Smith, D.T., Broughton, K.S. and LarsonMeyer, D.E. (2012) Vitamin D status and biomarkers of inflammation in runners. Open Access Journal of Sports Medicine, 3, 35-42.

[77] Salo, D.C., Donovan, C.M. and Davies, K.J. (1991) HSP70 and other possible heat shock or oxidative stress proteins are induced in skeletal muscle, heart, and liver 
during exercise. Free Radical Biology and Medicine, 11, 239-246. doi:10.1016/0891-5849(91)90119-N

[78] Guglielmo, C.G., Piersma, T. and Williams, T.D. (2001) A sport-physiological perspective on bird migration: Evidence for flight-induced muscle damage. The Journal of Experimental Biology, 204, 2683-2690.

[79] Liu, Y. and Steinacker, J.M. (2001) Changes in skeletal muscle heat shock proteins: Pathological significance. Frontiers in Bioscience, 6, D12-25. doi:10.2741/Liu

[80] Steinacker, J.M. and Liu, Y. (2002) Stress proteins and applied exercise physiology. In: Locke, M. and Noble, E.G., Eds., Exercise and Stress Response: The Role of Stress Proteins, CRC Press, Boca Raton, 197-216. doi:10.1201/9781420042016.ch11

[81] Kurek, J.B., Bower, J.J., Romanella, M., Koentgen, F., Murphy, M. and Austin, L. (1997) The role of leukaemia inhibitory factor in skeletal muscle regeneration. Muscle \& Nerve, 20, 815-822.

[82] Moresi, V., Pristerá, A., Scicchitano, B.M., Molinaro, M., Teodori, L., Sassoon, D., Adamo, S. and Coletti, D. (2008) Tumor necrosis factor-alpha inhibition of skeletal muscle regeneration is mediated by a caspase-dependent stem cell response. Stem Cells, 26, 997-100. doi:10.1634/stemcells.2007-0493

[83] Bhatnagar, S., Panguluri, S.K., Gupta, S.K., Dahiya, S., Lundy, R.F. and Kumar, A. (2010) Tumor necrosis factor- $\alpha$ regulates distinct molecular pathways and gene networks in cultured skeletal muscle cells. PLOS ONE, 5, e13262. doi:10.1371/journal.pone.0013262

[84] Schleithoff, S.S., Zittermann, A., Tenderich, G., Berthold, H., Stehle, P. and Koerfer, R. (2006) Vitamin D supplementation improves cytokine profiles in patients with congestive heart failure: A double-blind, randomized, placebo-controlled trial. The American Journal of Clini- cal Nutrition, 83, 754-759.

[85] Peterson, C.A. and Heffernan, M.E. (2008) Serum tumor necrosis factor-alpha concentrations in healthy women. Journal of Inflammation, 5, 10. doi:10.1186/1476-9255-5-10

[86] Shea, M.K., Booth, S.L., Massaro, J.M., Jacques, P.F., D'Agostino, R.B., Dawson-Hughes, B., Ordovas, J.M., O’Donnell, C.J., Kathiresan, S., Keaney, J.F., Vasan, R.S. and Benjamin, E.J. (2008) Vitamin K and vitamin D status: Associations with inflammatory markers in the Framingham offspring study. American Journal of Epidemiology, 167, 313-320.

[87] Lowery, L. and Forsythe, C.E. (2006) Protein and overtraining: Potential applications for free-living athletes. Journal of the International Society of Sports Nutrition, 3, 42-50.

[88] Long, C.L., Schaffel, N., Geiger, J.W., Schiller, W.R. and Blakemore, W.S. (1979) Metabolic response to injury and illness: Estimation of energy and protein needs from indirect calorimetry and nitrogen balance. Journal of Parenteral and Enteral Nutrition, 3, 452-456. doi: $10.1177 / 0148607179003006452$

[89] Williams, M. (2005) Nutrition for health fitness and sport. McGrow-Hill Publishing Company, Boston.

[90] Ament, W. and Verkere, G.J. (2009) Exercise and fatigue. Sports Medicine, 39, 389-422. doi:10.2165/00007256-200939050-00005

[91] Neto, J.C.R., Lira, F.S., Oyama, L.M., Zanchi, N.E., Yamashita, A.S., Batista, M.L., Oller do Nascimento, C.M. and Seelaender, M. (2009) Exhaustive exercise causes an anti-inflammatory effect in skeletal muscle and a pro-inflammatory effect in adipose tissue in rats. European Journal of Applied Physiology, 106, 697-704. doi:10.1007/s00421-009-1070-1 